\title{
Notch-acuity effects on the fracture toughness of saline ice
}

\author{
S.J. DeFranco, Y. Wei and J.P. Dempsey \\ Department of Civil and Environmental Engineering, Clarkson University, Potsdam, NY 13699-5710, U.S.A.
}

\begin{abstract}
Dynamic ocean-induced loading of ice has recently prompted interest in the fatigue strength of ice and, consequently, aspects of the fracture testing of ice need to be examined. One aspect in fracture testing, the effects of notch acuity on the apparent fracture toughness $\left(K_{\mathrm{Q}}\right)$ of saline ice, was investigated in this study using four groups of single-edge notched-bend specimens with different crack(or notch-) root radii, fabricated by four different methods; namely, drilling a small hole of two different radii at the crack tip, cutting a crack with a band saw and using a hand-held razor blade to scribe a sharp crack. For this study, tests were performed on saline ice using one crack length and orientation, constant thickness and constant temperature $\left(-25^{\circ} \mathrm{C}\right)$. The mean values and the standard deviations of the apparent fracture toughness of the specimens with blunt notches were higher than those with sharp cracks. The results presented in a plot of fracture toughness versus $\sqrt{\rho}$, where $\rho$ is the crack-tip radius, provide a preliminary estimate of the required notch acuity for fracture-toughness testing of saline ice.
\end{abstract}

\section{INTRODUCTION}

The effects of dynamic ocean forces on ice (e.g. waveinduced flexure and break-up of ice sheets and the breakoff of glacier tongues) have recently prompted interest in the fatigue strength of ice and the effect of cyclic loading on crack growth in ice. These investigations, presently being completed on fresh-water ice (Nixon and Weber, 1991), used the results of a study on notch-acuity (or crack-tip sharpness) effects on the fracture toughness of fresh-water ice (Wei and others, 1990), which is the analogue of this saline-ice study.

When considering the applicability of linear elastic fracture mechanics (LEFM) to a material, several criteria must be met. The crack in the fracture-toughness specimen must be large in comparison to the micro-structure, the crack-tip process zone must be very small with respect to the smallest dimension of the specimen and the crack-tip radius must be less than a certain, as yet unknown, radius. For fresh-water ice, Wei and others (1990) have established this radius to be approximately $0.01 \mathrm{~mm}$.

The significance of the effects of notch acuity, or cracktip sharpness, on the fracture toughness of ice was shown by Wei and others (1990) for S2 fresh-water columnar ice at $-10^{\circ} \mathrm{C}$. In that study, the apparent fracture toughness was found, for specimens containing blunt notches, to be up to $96 \%$ higher than specimens containing sharp cracks. Cracks were fabricated by the authors using six different methods, namely, (A) drilling a $2 \mathrm{~mm}$ hole at the notch root, (B) cutting a notch with a band saw,

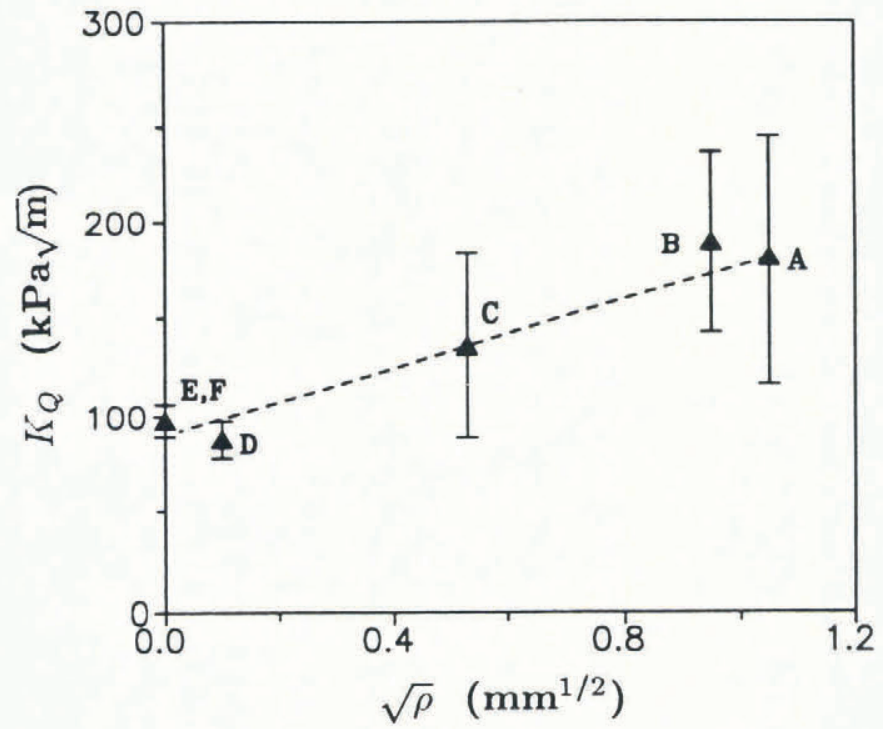

Fig. 1. Effects of notch-root radii on $K_{Q}$ of fresh-water columnar ice at $-10^{\circ} \mathrm{C}$.

(C) cutting a notch with a $0.2 \mathrm{~mm}$ diamond-coated wire saw, (D) freezing in a lubricated razor blade, (E) scribing with a razor blade and $(\mathrm{F})$ pre-cracking. The results of these experiments are shown in Figure 1. The effect of notch acuity is shown to be quite significant in terms of increased apparent fracture toughness $\left(K_{\mathrm{Q}}\right)$ and scatter of results for groups A, B and C. For groups D, E and F, $K_{\mathrm{Q}}$ is significantly lower in magnitude and scatter; for 
group $\mathrm{D}$, it is interesting to note that the magnitude and scatter for $K_{\mathrm{Q}}$ is lower than that for groups $\mathrm{E}$ and $\mathrm{F}$. This was attributed by the authors to, possibly, a reduction of the fracture-surface energy at the crack tip due to lubricant applied to the razor blade before crack formation. Another salient feature of the study by Wei and others was the influence of the micro-structure on the apparent fracture toughness. For groups B-D, in many instances, thin sections of cracked specimens revealed that fracture occurred at locations away from the notch root often at a grain boundary. In these cases, the load required to propagate the crack was typically much higher than those cases where fracture initiated from the notch root. Essentially, the micro-structure in the former cases is more influential because the "stress singularity" does not dominate; therefore, groups B-D also exhibit an increased scatter of $K_{\mathrm{Q}}$ results. Fracture usually occurred at the corners of the rectangular-ended notches of group B. This was attributed to the stress concentration at the corners of re-entrant notches of this type. For groups $\mathrm{E}$ and F, fracture always occurred from the scribed or precracked notch tip. Major conclusions of that paper were that scribing a crack with a razor blade or pre-cracking produces a reliable, repeatable method of crack formation for fresh-water, columnar ice and that notch-acuity effects account for at least some of the scatter found in the literature for ice fracture-toughness results.

The effects of notch acuity on the fracture toughness of sea ice have for the most part been ignored by researchers, although, in the majority of studies, an attempt was made to induce sharp cracks in the notchedfracture specimens. Vaudrey (1977), in a study of the mechanical properties of sea ice, found that the fracture toughness of in situ beams was apparently a function of the square root of the brine volume. In figure 27 of his report, however, it can be seen that the data are very scattered around the small range of test temperatures and it might be surmised that some of the scatter was caused by notch-acuity effects of crack preparation or by notch blunting due to the crack tips being in contact with cold sea water. The cracks Vaudrey fabricated in his specimens are described as "saw-cut notches" which were possibly very blunt.

Several other studies on the fracture toughness of sea ice exist in the literature, where a sharp crack was created by reshaping the band saw-cut notches by a razor blade having a radius of curvature of $0.1 \mathrm{~mm}$ (Urabe and others, 1980; Urabe and Yoshitake, 1981a,b). There is no description in those papers as to what reshaping means, although it is interpreted here to mean rubbing the razor along the crack front in order to sharpen the blunt notch. These tests were also performed in situ, again raising the question of notch blunting due to direct exposure to sea water.

Timco and Frederking (1983) used a surgeon's scalpel in order to generate sharp cracks in fracture-toughness specimens of Beaufort Sea ice. Like Vaudrey (1977), they too found a brine volume influence on the fracture toughness, but with much less scatter in the fracture-toughness results than the previous author. The sea-ice specimens tested by Timco and Frederking were isothermal when tested, as the ice was transported to a cold room after being harvested. It is not clear whether the scalpel was used to scribe a crack or to "reshape" the crack, as mentioned previously.

Tuhkuri (1987) addressed the issue of notch-acuity effects on the fracture toughness of sea ice but found that the existence of a sharp crack did not influence the fracture-toughness results. Tuhkuri conjectured that either the sharpened notches were still too blunt or that, when subjected to loading, a large plastic zone developed at the crack tip, thereby blunting the sharp crack. Additionally, he included the possibility of crack-length effects and the existence of a micro-cracked zone at the crack tip instead of a plastic zone. The cracks were formed by first cutting a blunt notch with a chain saw and then sharpening the notch with a "specially machined sharpening blade". All tests were performed in situ.

The above review of typical macro-crack formation procedures in sea ice is not intended to be comprehensive; instead it provides a general view of the current practice of fracture-toughness testing on sea ice. In this study, fracture-toughness tests were performed on saline ice using several methods of crack-tip formation. Some of the methods, as will be seen in the next section, are not useful for common fracture-toughness evaluation but serve to illustrate the importance of having a sharp crack in order to reduce scatter in the fracture-toughness results of sea ice and to duplicate more accurately the sharp-crack assumption of LEFM.

\section{EXPERIMENTAL PROCEDURE}

The saline ice used in this study was grown in a cold room at Clarkson University during July and August 1990 in a $1.21 \times 1.09 \times 0.76 \mathrm{~m}^{3}$ tank using Potsdam tap water and Morton Purex salt $(99.85 \% \mathrm{NaCl}$; Morton International, Inc. 1985). Due to the small size of the tank and brine drainage during solidification, $\mathrm{NaCl}$ was initially added to raise the salinity of the water to approximately $26 \%$. Subsequent salinity measurements after harvesting revealed the salinity of the remaining water to be approximately $32-34 \%$, which is comparable to that of sea water.

The brine solution was cooled uniformly to temperatures near freezing by circulating the solution through the $-25^{\circ} \mathrm{C}$ air above the tank. When the water temperature was approximately $0^{\circ}-1^{\circ} \mathrm{C}$, the water surface was spray-seeded by a cold saline solution $\left(26^{\circ} \%\right.$ ) in order to initiate columnar growth. The ice grew for approximately $48 \mathrm{~h}$ at $-25^{\circ} \mathrm{C}$ to a thickness of 15 to $20 \mathrm{~cm}$.

Upon harvesting, the rough cut beams were transferred to another cold room having an ambient temperature of $-25^{\circ} \mathrm{C}$. The beams were wrapped in plastic to prevent sublimation and stored with the top of the ice surface down in order to reduce brine drainage. Some brine drainage was apparent, however, on the top surface of the isothermal beams $\left(-25^{\circ} \mathrm{C}\right)$ in the form of a thin, white ice layer. This layer was removed from each specimen during final preparation. The beams were stored in these conditions for a minimum of $24 \mathrm{~h}$ to allow them to equilibrate to room temperature which, being below the eutectic point of $-21.2^{\circ} \mathrm{C}$, ensured a two-phase solid (ice - $\mathrm{NaCl} \cdot 2 \mathrm{H}_{2} \mathrm{O}$; Assur, 1958).

Vertical thin sections showed a small layer of very finegrained ice about $5 \mathrm{~mm}$ thick at the top surface of the 
ice sheet and a columnar zone throughout the remaining thickness of each sheet. Horizontal thin sections revealed that the saline ice had a columnar structure with an average grain-size $d_{\mathrm{av}}$ of approximately $15 \mathrm{~mm}$ and a randomly horizontal $c$-axis orientation which is typical of seeded ice formed under quiescent conditions. Salinity measurements of the ice were taken from the meltwater of fractured specimens using a digital salinity meter with automatic temperature compensation and are given versus depth in Table 1 . A depth of $0 \mathrm{~mm}$ indicates an orientation of the specimen side $w$ closest to the

Table 1. Ice salinities and densities

\begin{tabular}{rcccc}
\hline Depth & \multicolumn{3}{c}{ Salinity (\%) } & Density \\
& & & & \\
$(\mathrm{mm})$ & $0-25$ & $25-50$ & $50-75$ & $\mathrm{~kg} \mathrm{~m}^{-3}$ \\
\hline Sheet 3 & 7.0 & 5.5 & 6.1 & $917.6 \pm 4.6$ \\
4 & 7.5 & 6.0 & 5.6 & $906.2 \pm 6.5$ \\
$5 *$ & - & - & - & $906.3 \pm 7.0$ \\
$6 *$ & - & - & - & $917.5 \pm 1.5$
\end{tabular}

* Salinities were not measured due to instrument malfunction.

top of the ice sheet whereas larger depths indicate salinity measurements with increasing specimen thickness $h$ and hence increasing ice-sheet depth. Density measurements were made recording the mass of a known volume of sea ice. The mass of each density sample was measured on a digital scale with an accuracy of $0.1 \mathrm{~g}$ and volume was measured using digital calipers accurate to $0.01 \mathrm{~mm}$. Density measurements for each ice sheet tested are also given in Table 1.

Specimens were formed for testing under four point loading by planing the rough cut beams with a planerjointer. Orthogonality and parallelism of the sides of each specimen was ensured by this method and the planed sides of each specimen were measured to be parallel within $0.5 \mathrm{~mm}$ on a comparator. The geometry and orientation of the crack with respect to the microstructure is shown in Figure $2(S=4 w, D=2 w, \epsilon=$ $w / 4, a / w=0.5, h \approx 75 \mathrm{~mm}$ and $w=150 \mathrm{~mm}$ ). In each case, the crack front was parallel to the direction of columnar growth (i.e. radial cracking). The stress intensity factor for this geometry is given in Tada and others (1973) and for fracture

$$
K_{\mathrm{Q}}=\frac{3 P_{f}}{h w} \sqrt{\pi a} F(a / w),
$$

where

$$
F(\xi)=1.12-1.40 \xi+7.33 \xi^{2}-13.08 \xi^{3}+14.00 \xi^{4}
$$

and $a, w$, and $h$ are defined in Figure 2.

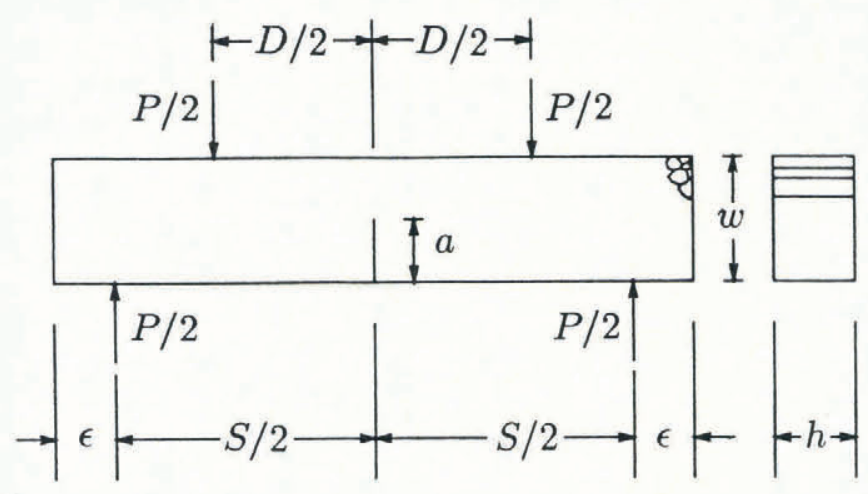

Fig. 2. Four-point bend geometry and ice orientation.

The formation of notches and cracks was accomplished by different methods for the specimens in each group. A drill of $3.175 \mathrm{~mm}$ in diameter was used to drill a small hole at the notch root for the specimens of group A. (A crack was initially formed using a band saw.) The average-root radius was measured to be approximately $1.60 \mathrm{~mm}$. For group B, a $1.95 \mathrm{~mm}$ drill was used to create a notch-root radius of $1.1 \pm 0.08 \mathrm{~mm}$ in a fashion identical to that of group A. The notches in the specimens of group $\mathrm{C}$ were simply cut by a band saw, resulting in a rectangular-ended root of width $1.8 \pm 0.2 \mathrm{~mm}$. For the specimens of group D, the notches were cut by a band saw and sharpened by scribing a hand-held razor blade across the notch just prior to testing. This generated a sharp crack of uneven length ( $\sim 2 \mathrm{~mm}$ long) from the band saw-cut notch. For group D, the crack length used in (1) was the sum of the band saw-cut notch and the average length of the sharp crack. All machining, storage and testing were performed at $-25^{\circ} \mathrm{C}$. Testing was performed on a displacement-controlled ATS 1100SE universal testing frame with a crosshead speed of $7.62 \mathrm{~mm} \mathrm{~min}^{-1}$ and data were sampled at $1000 \mathrm{~Hz}$ using a Keithley Series 500 analog to digital converter. All data were processed by a Zenith Z248 micro-computer.

\section{RESULTS AND DISCUSSION}

Fracture initiating from the stationary macro-crack was unstable in each case. No previous crack growth occurred prior to catastrophic failure of each specimen. Figure 3 shows a typical plot of load versus time during the fracture experiment and the maximum load $\left(P_{f}\right)$ from each plot was used in (1), as this was the load at instability in each case. The load versus time plot was essentially linear up to the maximum load for each fracture experiment. Times to fracture ranged from 0.3 to $1.9 \mathrm{~s}$, causing a loading rate $K$ of 313 to $89 \mathrm{kPa} \sqrt{m} \mathrm{~s}^{-1}$, respectively.

Due to the size of each specimen, it should be noted that only five specimens could be harvested from each ice sheet and, therefore, only a limited number of test results are available at this time. Preliminary results of fracture experiments are shown in Figure 4, where each group is represented as an average of four experiments. It is recognized that a larger amount of data is required for each group and that a wider range of notch radii need to 


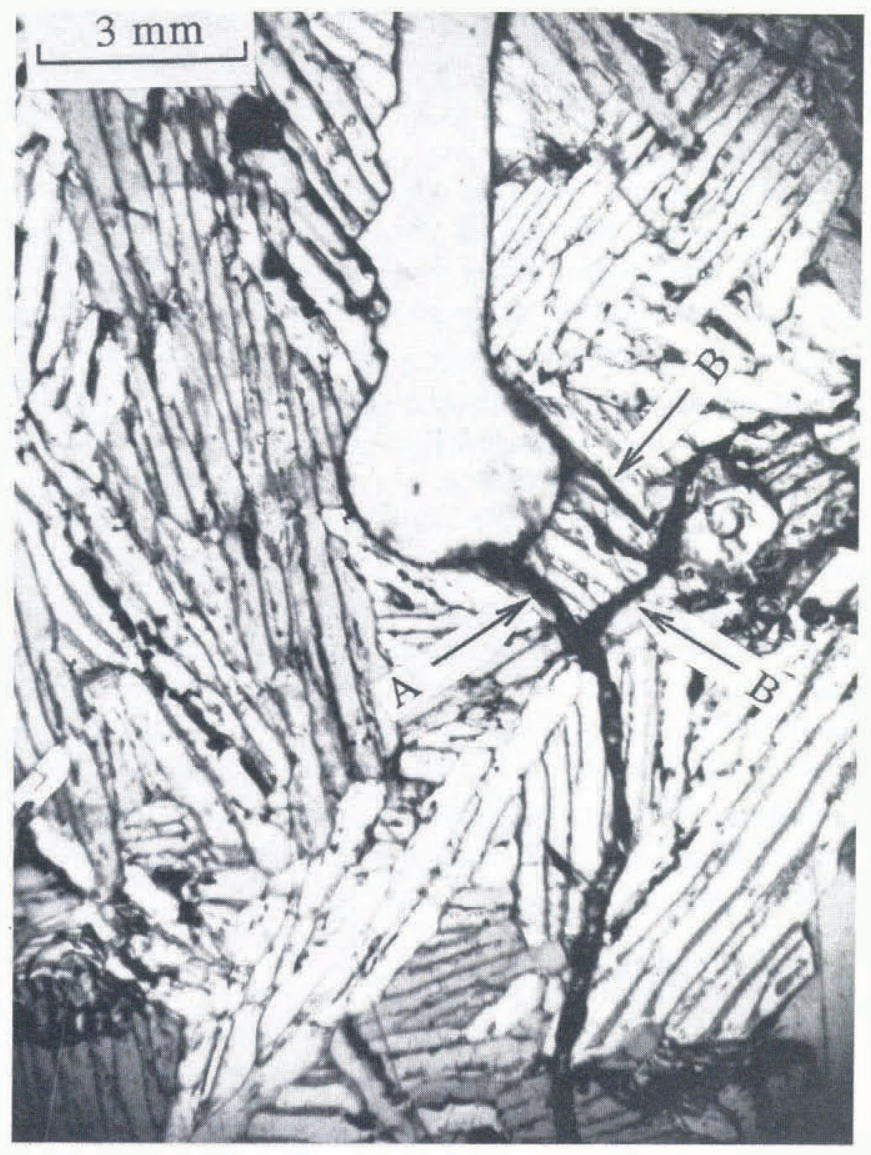

(a)

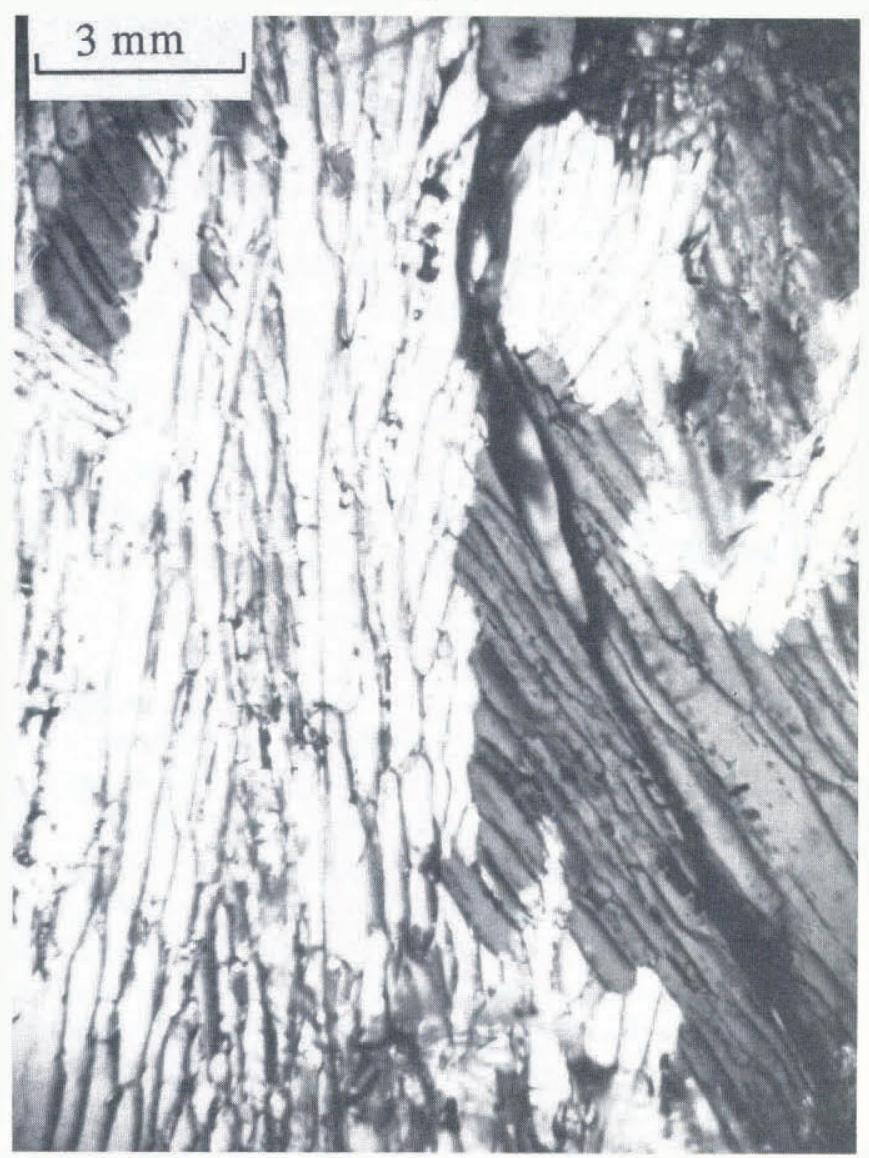

(c)

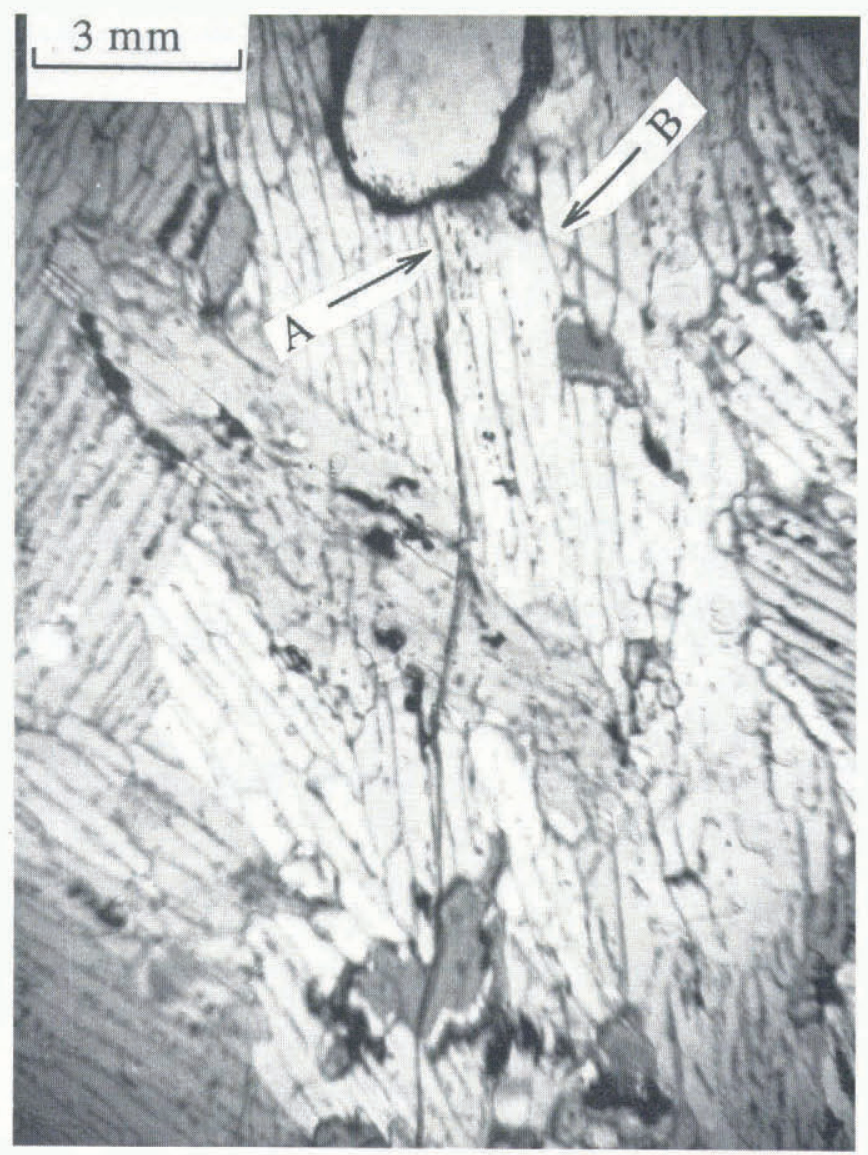

(b)
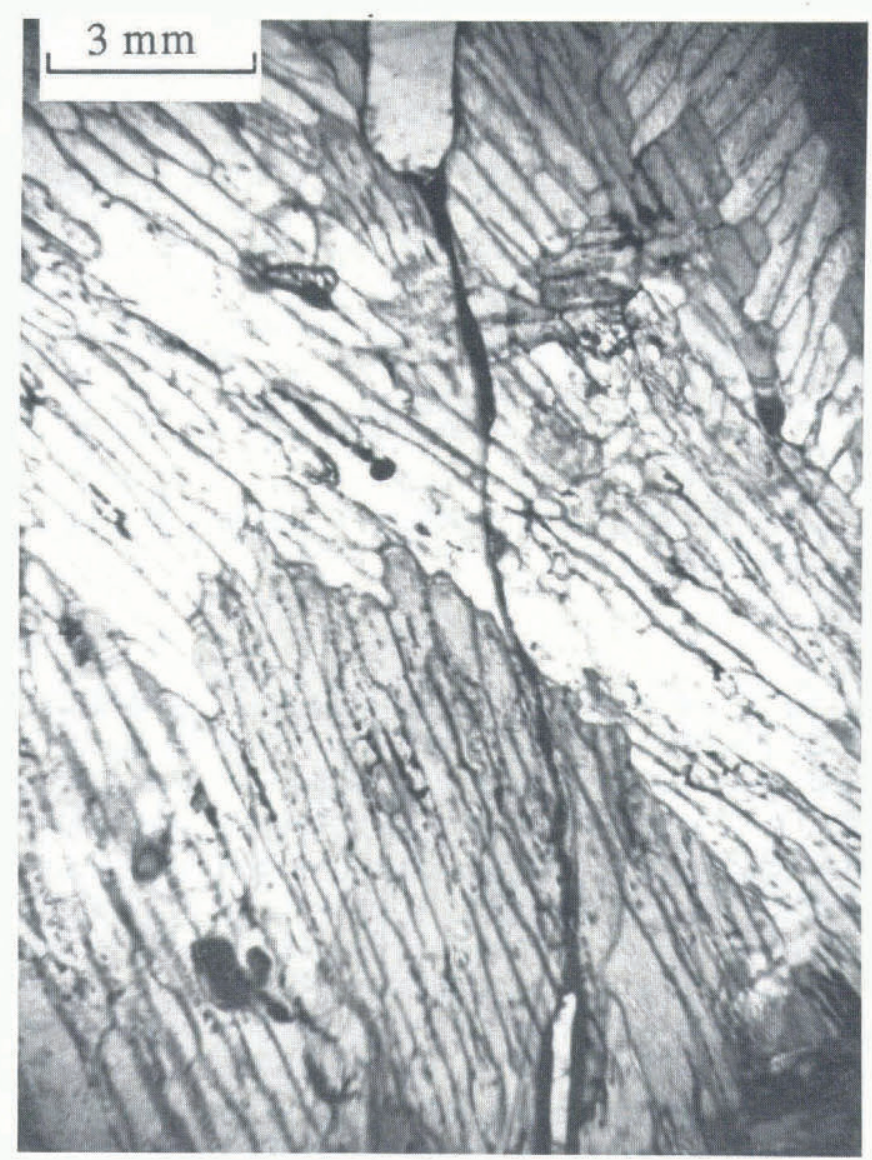

(d)

Fig. 5. Notch geometries: (a) group A, (b) group B, (c) group C, (d) group D. 


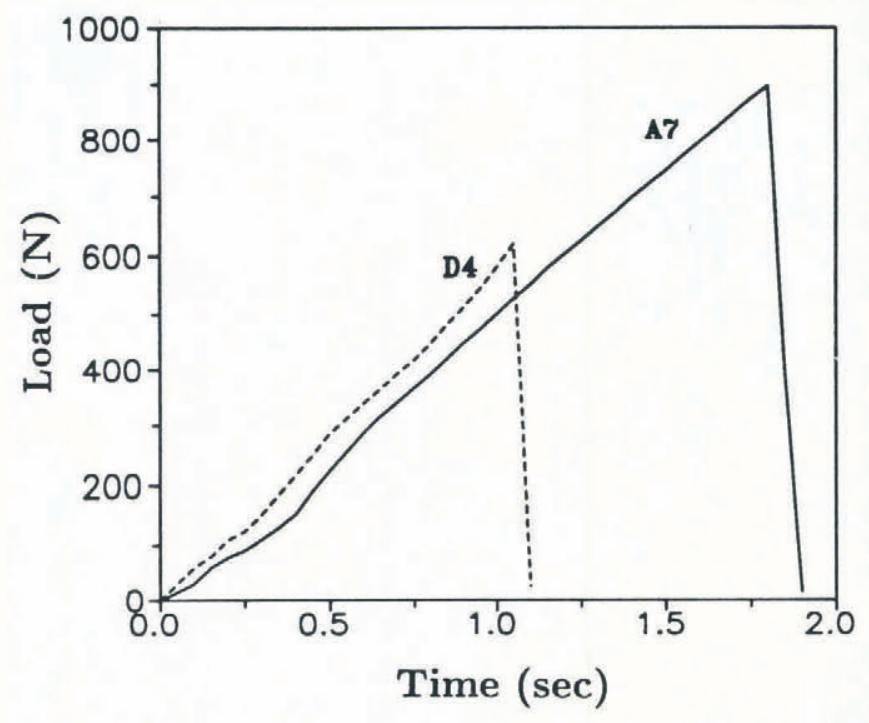

Fig. 3. Typical load versus time plot for saline-ice beams.

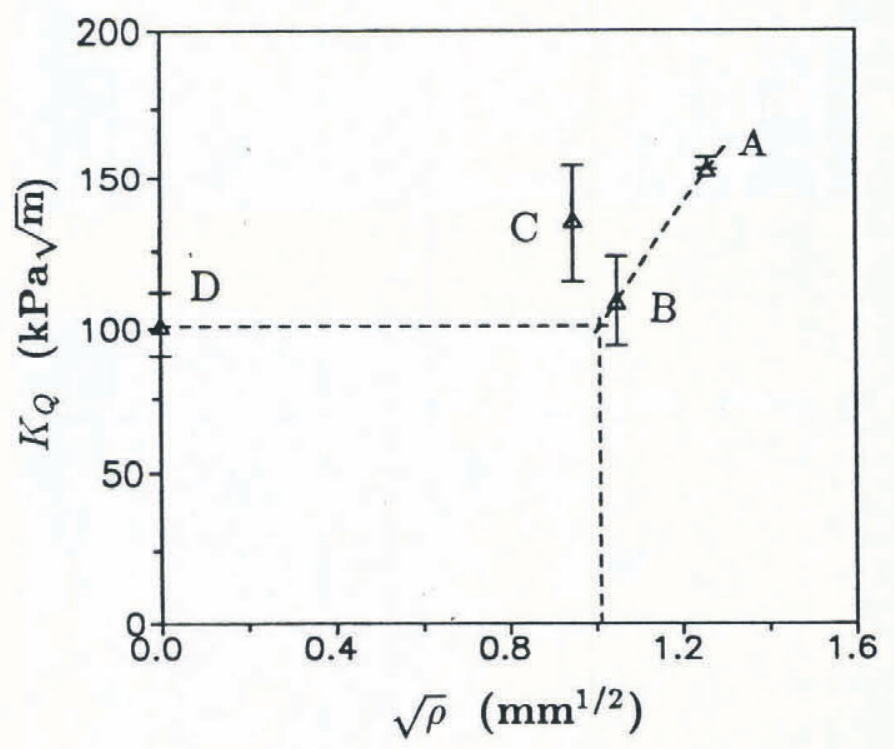

Fig. 4. Effects of notch-root radii on $K_{Q}$ of saline $i c e$.

be examined for any conclusion to be statistically valid. From Figure 4, however, a trend of decreasing $K_{\mathrm{Q}}$ with decreasing $\sqrt{\rho}$ is apparent and, at least between groups $\mathrm{B}$ and $\mathrm{D}$, it is not as dramatic a trend as was shown by Wei and others (1990) for fresh-water, columnar ice. The effects of notch acuity appear to be more severe in groups $\mathrm{A}$ and $\mathrm{C}$ as the $K_{\mathrm{Q}}$ values for these groups are, respectively, 150 and $122 \%$ higher than group D. Also evident from Figure 4 is the possible existence of a critical crack-tip radius $\rho_{0}$ which is indicated by the intersection of the dashed lines. $\rho_{0}$ is the minimum notch radius necessary to satisfy the sharp crack criterion of LEFM. For metallic materials there is a critical value $\rho_{0}$ above which $K_{\mathrm{lc}}$ has a linear dependence on $\sqrt{\rho}$ and below which the plane-strain fracture-toughness $K_{\text {Ic }}$ is obtained (Irwin, 1964; Wilshaw and others, 1968; Knott, 1973). No such critical notch radius was found in this study, or is to be implied from Figure 4, although more experiments will be performed using intermediate notch radii (i.e. $\rho_{\mathrm{D}} \leq \rho \leq \rho_{\mathrm{A}}$ ) in order to investigate the existence of $\rho_{0}$ for saline ice.

An extremely interesting feature of the fracture of saline ice can be seen in photographs (5x magnification) of fractured specimens for each group (Fig. 5). In each photograph, fracture initiated in the direction parallel to the long direction of the pure-ice platelets which characterize the substructure of saline ice. Along the boundaries of the platelets are the brine inclusions which contain brine and solid salts (Weeks and Ackley, 1982). However, fracture did not always initiate as just described. In a few cases, the orientation of the substructure was apparently not an easy path for initiation and fracture occurred at angles to the ice platelets. It is not clear whether the fracture load was higher in these cases and only with more experiments will this issue be resolved. In Figures $5 \mathrm{a}$ and 5b, specimens A6 and B4, respectively, the arrows labeled A indicate the crack path while those labeled B indicate damage created during thin sectioning.

\section{CONCLUSIONS}

- Photo-micrographs revealed that, in almost all cases, fracture initiated parallel to the platelet sub-structure of grains oriented most favorably to the crack tip.

- $K_{\mathrm{Q}}$ for cold, saline ice of constant temperature $\left(-25^{\circ} \mathrm{C}\right)$ shows an apparent decreasing trend with decreasing notch-root radius, although more work is needed to verify this trend experimentally.

- Saline ice is apparently not as sensitive to notch acuity for intermediate notch-root radii as fresh-water columnar ice, at least at the temperature used for this study. This is believed to be caused by the extreme differences in the micro-structure of saline ice as compared to fresh-water columnar ice. It remains to be seen how the effects of higher brine volume in conjunction with notch acuity will affect the apparent fracture toughness.

- Scribing a crack is a repeatable and reliable method for forming a sharp crack in fracture-toughness specimens of saline ice.

\section{ACKNOWLEDGEMENTS}

The authors thank Mr Philip Parker for his assistance in the experimental phase of this study and $\mathrm{Mr}$ Carl Davey for development of the four point loading apparatus. This research was supported in part by the U.S. Office of Naval Research under Grant no. N00014-90-J1360 and in part by the U.S. National Science Foundation under Grant no. MSM-86-18798. Mr Parker was supported under a grant by the U.S. National Science Foundation's Research Experience for Undergraduates Program.

\section{REFERENCES}

Assur, A. 1958. Composition of sea ice and its tensile strength. In Arctic Sea Ice. Conference held at Easton, Maryland, February 24-27, 1958. Washington, DC, National Academy of Sciences - Na- 
tional Research Council, 106-138. (Research Publication 598.)

Irwin, G.R. 1964. Structural aspects of brittle fracture. Appl. Materials Res., 3, 65-81.

Knott, J.F. 1973. Fundamentals of fracture mechanics. London, Butterworths.

Morton International, Inc. [n.d.] Morton salt product data. Purex and TFC Purex Salts. Chicago, IL, Morton International Inc. (PDS No. 105.1, 5/85.)

Nixon, W. and L. Weber. 1991. Fatigue crack growth in fresh-water ice: preliminary results. Ann. Glaciol., 15, 236-241.

Tada, H., P.C. Paris, and G.R. Irwin. 1973. The stress analysis of cracks handbook. St. Louis, MO, Del Research Group.

Timco, G.W. and R.M.W. Frederking. 1983. Flexural' strength and fracture toughness of sea ice. Cold Reg. Sci. Technol., 8(1), 35-41.

Tuhkuri, J. 1988. The applicability of LEFM and the fracture toughness $\left(K_{I C}\right)$ to sea ice. In Sackinger, W.M. and M.O. Jeffries, eds. Port and ocean engineering under Arctic conditions. Vol. 1. Fairbanks, AK, University of Alaska. Geophysical Institute, 2132 .

Urabe, N. and A. Yoshitake. 1981a. Fracture toughness of sea ice - in-situ measurement and its application. POAC 81. The Sixth International Conference on Port and Ocean Engineering under Arctic Conditions. Québec, Canada, July 27-31, 1981. Proceedings. Vol. 1. Québec, Université Laval, 356-365.

Urabe, N. and A. Yoshitake. 1981b. Strain rate depen- dent fracture toughness $\left(K_{I C}\right)$ of pure ice and sea ice. IAHR International Symposium on Ice, Québec, Canada, July 27-31, 1981. Proceedings. Vol. 2. Québec, Université Laval, 551-563.

Urabe, N., T. Iwasaki, and A. Yoshitake. 1980. Fracture toughness of sea ice. Cold Reg. Sci. Technol., 3(1), 29-37.

Vaudrey, K.D. 1977. Ice engineering-study of related properties of floating sea-ice sheets and summary of elastic and viscoelastic analyses. Port Hueneme, CA, Naval Construction Battalion Center. Civil Engineering Laboratory. (Technical Report 860.)

Weeks, W.F. and S.F. 1982. The growth, structure, and properties of sea ice. CRREL Monogr. 82-1.

Wei, Y., S.J. DeFranco, and J.P. Dempsey. 1990. Notch acuity effects on the fracture toughness of freshwater columnar ice. In Ayorinde, O.A., N.K. Sinha, and D.S. Sodhi, eds. Proceedings of the Ninth International Conference on Offshore Mechanics and Arctic Engineering - 1990 - presented at ... Houston, Texas, February 18-23, 1990. Vol. 4. Arctic/polar technology. New York, American Society of Mechanical Engineers, 253-257.

Wilshaw, T.R., C.A. Rau, and A.S. Tetelman. 1968. A general model to predict the elastic-plastic stress distribution and fracture strength of notched bars in plane strain bending. Eng. Fract. Mech., 1, 191-211.

The accuracy of references in the text and in this list is the responsibility of the authors, to whom queries should be addressed. 